\title{
Endovascular Treatment for Idiopathic Intracranial Hypertension Improves Clinical Symptoms and Signs
}

\section{Tratamento endovascular para hipertensão intracraniana idiopática melhora sinais e sintomas clínicos}

\author{
João Miguel Almeida Silva ${ }^{1}$ Mario Luiz Marques Conti ${ }^{1}$ Guilherme Brasileiro Aguiar ${ }^{1}$ Mauricio Jory ${ }^{1}$ \\ Paulo Helio Monzillo ${ }^{1}$ José Carlos Esteves Veiga ${ }^{1}$ \\ ${ }^{1}$ Faculdade de Ciências Médicas, Santa Casa de São Paulo, São Paulo, \\ SP, Brazil \\ Arq Bras Neurocir 2017;36:1-6. \\ Address for correspondence João Miguel Almeida Silva, Resident, \\ School of Medical Sciences, Faculdade de Ciências Médicas da Santa \\ Casa de São Paulo, Rua Doutor Cesário Motta Júnior, 61 - Vila Buarque, \\ São Paulo, SP, Brazil, 01221-020 \\ (e-mail: joaomiguelneuro@hotmail.com).
}

\begin{abstract}
Keywords

- cerebral angiography

- endovascular procedures

- pseudotumor cerebri
\end{abstract}

\section{Resumo}

Introduction New physiopathological concepts regarding idiopathic intracranial hypertension $(\mathrm{IIH})$ recommend the endovascular treatment in refractory patients with transverse sinus stenosis.

Objectives To assess the role of the transverse sinus stenting treatment in the symptomatology of patients with $\mathrm{IH}$.

Method Clinically refractory patients with impaired venous drainage of the transverse sinus were submitted to cerebral angiographies. Patients with pre and poststenotic pressure gradients $>8 \mathrm{mmHg}$ were submitted to endovascular treatment.

Results Seven patients underwent cerebral angiography with manometry. Stenting was performed in six cases after pressure gradient assessment. All cases showed improvements in headache and resolution of papilledema.

Discussion and Conclusion Although the role of endovascular therapy should be further studied, our data suggest it may improve the clinical symptoms and signs of $\mathrm{IIH}$ in selected patients.

Introdução Novos conceitos fisiopatológicos a respeito da hipertensão intracraniana idiopática (HII) propõem, em casos refratários, o tratamento endovascular em pacientes com estenose no seio transverso.

Objetivos Avaliar o efeito do tratamento endovascular, realizado pela implantação de um stent no seio transverso, em pacientes com HII.

Método Pacientes refratários clinicamente com alterações da drenagem venosa no seio transverso foram submetidos a angiografia cerebral. Diante de gradientes pressóricos pré e pós-estenóticos maiores do que $8 \mathrm{mmHg}$, foi feito o tratamento endovascular. received

September 16, 2016

accepted

November 24, 2016
DOI http://dx.doi.org/

10.1055/s-0036-1597820. ISSN 0103-5355.
Copyright (e 2017 by Thieme Revinter

Publicações Ltda, Rio de Janeiro, Brazil
License terms

(이요 $\Theta \circledast$ 
Palavras-chave

- angiografia cerebral

- procedimentos endovasculares

- pseudotumor cerebral
Resultados Sete pacientes realizaram angiografia cerebral com manometria. A colocação de stent foi realizada em seis após avaliação do gradiente pressórico. Todos apresentaram melhora da cefaleia, com resolução do papiledema.

Discussão e Conclusão Apesar de o papel do tratamento endovascular para HII necessitar de mais estudos, nossos dados sugerem que ele pode melhorar sinais e sintomas relacionados à HII em pacientes selecionados.

\section{Introduction}

Idiopathic intracranial hypertension (IIH) is a rare clinical entity with a series of known symptoms and numerous possible etiologies, which in most cases are unidentified. ${ }^{1}$ The historical name for IIH is pseudotumor cerebri, given the symptomatology of elevated intracranial pressure mimicking other conditions, such as brain tumors in the absence of diagnosed brain abnormalities. ${ }^{1}$

The first description of intracranial hypertension without an apparent cause was reported by Heinrich Quincke. ${ }^{2}$ It was only in 1955 that Foley proposed the name "benign intracranial hypertension" to reflect its clinical course associated with remission and no brain tumors. ${ }^{1}$

However, the absence of identifiable etiologies, a situation occurring in up to $90 \%$ of cases, and a course often associated with progressive loss of vision, led to the name being changed to idiopathic intracranial hypertension. ${ }^{3}$

Idiopathic intracranial hypertension patients typically present with headaches, visual impairments, pulsatile tinnitus and papilledema. ${ }^{4}$ The most prevalent morbidity is progressive visual loss, seen in up to $25 \%$ of cases, but it can be rapid in up to $3 \%$ of patients. ${ }^{5}$ Impairment of the cranial nerves, excluding the optic nerve, can occur in up to $20 \%$ of cases. ${ }^{6}$

Although IIH is known to predominantly affect overweight women of childbearing age, numerous hypotheses exist to explain the potential mechanisms of the elevated intracranial pressure. As discussed by Walker in 2001, mechanisms involving increased interstitial fluid volume, blood volume, brain tissue volume or cerebrospinal fluid (CSF) production are the most plausible, as are those increasing CSF absorption resistance and elevating cerebral venous pressure. $^{7}$ There are other clinical conditions associated with IIH symptoms whose cause-effect relationship are not well established, including vitamin A deficiency and hypervitaminosis $A$, the use of pharmacological agents (oral retinoids, tetracycline derivatives, indomethacin, lithium, anabolic steroids, tamoxifen), pregnancy, menstrual changes, and systemic diseases (systemic arterial hypertension, diabetes mellitus, thyroid changes, hypoparathyroidism). ${ }^{8}$

Lesions that raise cerebral venous pressure, such as cerebral arteriovenous malformations, ${ }^{9}$ thrombosis of the venous sinuses ${ }^{10}$ or their occlusion by tumors, ${ }^{11}$ are associated with symptoms resembling those of IIH, due to an underlying resistance to CSF absorption.

Since the 1990s, studies investigating cerebral venous pressure have been conducted in IIH patients. The results of studies by King ${ }^{12}$ and Karahalios ${ }^{13}$ further support the theory of obstruction in the cerebral venous outflow. The observation of elevated venous pressures confirmed by manometry during cerebral venography in IIH patients suggests that the occurrence of stenosis of cerebral venous sinuses may be associated with the clinical condition. The results of the study conducted by Farb et al, in which 93\% of IIH patients had stenosis of the transverse sinus on magnetic resonance imaging (MRI), ${ }^{14}$ lend credence to the notion of obstruction in the cerebral venous outflow.

The most commonly used treatment is acetazolamide, a carbonic anhydrase inhibitor that lowers intracranial and intraocular pressures. ${ }^{15}$ Recently, topiramate became an additional option, exhibiting similar effects and good analgesic action, while also favoring weight loss. ${ }^{16}$ Surgical management is reserved for refractory patients. ${ }^{17,18}$ A cerebrospinal fluid shunting can be performed to relieve intracranial pressure. ${ }^{17}$ Less frequently, fenestration of the optic nerve may be indicated to preserve visual function. ${ }^{18}$

Based on recent physiopathological concepts, stenting in the dural sinus has been recommended in selected cases after detection of pressure variation caused by sinus stenosis. The extent to which intracranial pressure elevation is the cause or consequence of venous sinus stenosis is unclear, but the procedure has gained increasing popularity. ${ }^{19}$

\section{Objectives}

To describe the technique and to analyze the clinical outcomes of IIH patients submitted to stenting in the transverse sinus.

\section{Methods}

Between 2012 and 2013, 7 patients were referred for diagnostic cerebral angiography with manometry for IIH. Of those 7 patients, 6 met the criteria for transverse sinus stenting, having pressure gradients $>8 \mathrm{~mm} \mathrm{Hg}$ (-Table 1).

The patients were followed by the neurology service and referred for the procedure after confirmation of being clinically refractory with persistent elevated intracranial pressure despite the measures employed.

Out of the six patients submitted to the endovascular treatment, one individual was male, and the remainder, female. Their mean age on the date of the treatment was 39.8 years.

The study included patients meeting the diagnostic criteria for IIH, as defined by Friedman \& Jacobsen, ${ }^{20}$ who recently updated the modified Dandy criteria. The new criteria are more pertinent, following the inclusion of MRI 
Table 1 Patients submitted to cerebral angiography for IIH

\begin{tabular}{|c|c|c|c|c|c|c|c|c|c|c|c|c|}
\hline \multirow[t]{2}{*}{ Sex } & \multirow[t]{2}{*}{ Age } & \multicolumn{2}{|l|}{ LP } & \multicolumn{2}{|c|}{$\mathrm{CN}$} & \multicolumn{2}{|l|}{ OD } & \multicolumn{2}{|c|}{ Gradient } & \multirow[t]{2}{*}{ STENT } & \multirow[t]{2}{*}{ Outcome } & \multirow{2}{*}{$\begin{array}{l}\text { Follow-up } \\
\text { (months) }\end{array}$} \\
\hline & & Pre & Post & & & & & & & & & \\
\hline $1-\mathrm{F}$ & 28 & 40 & 25 & $\mathrm{VI}$ & - & Papilledema & Clear Borders & 11 & 2 & TS R & Improvement & 16 \\
\hline $2-F$ & 31 & 48 & 27 & - & - & Papilledema & Clear Borders & 12 & 2 & TS R & Asymptomatic & 12 \\
\hline $3-F$ & 43 & 36 & 24 & - & - & Papilledema & Clear Borders & 10 & 1 & TS R & Asymptomatic & 10 \\
\hline $4-F$ & 53 & 38 & 23 & - & - & Papilledema & Clear Borders & 9 & 1 & TS R & Asymptomatic/ transient & 10 \\
\hline $5-M$ & 22 & 30 & 23 & - & - & Clear Borders & Clear Borders & 15 & 2 & TS L & Improvement & 8 \\
\hline $6-F$ & 30 & $17-30$ & - & - & - & OD Atrophy & OD Atrophy & 1 & - & - & Intermittent & - \\
\hline $7-F$ & 22 & 48 & 26 & $\mathrm{VI}$ & - & Papilledema & Clear Borders & 17 & 2 & TS L & $\begin{array}{l}\text { Asymptomatic/transient } \\
\text { headache }\end{array}$ & 7 \\
\hline
\end{tabular}

Abbreviations: CN, cranial nerve; F, female; IIH, idiopathic intracranial hypertension; L, left; LP post, post-intervention lumbar puncture manometry ( $\left.\mathrm{cm} \mathrm{H} \mathrm{H}_{2} \mathrm{O}\right)$; LP pre, pre-intervention lumbar puncture manometry $\left(\mathrm{H}_{2} \mathrm{O} \mathrm{cm}\right)$; $M$, male; OD, optic disc; $\mathrm{R}$, right; TS, transverse sinus.

findings and additional etiologies for intracranial hypertension, such as cerebral venous thrombosis (-Table 2 ).

Lumbar manometry readings were high $\left(>25 \mathrm{~cm} \mathrm{H}_{2} \mathrm{O}\right)$ in all 6 patients, with a mean value of $40 \mathrm{~cm} \mathrm{H}_{2} \mathrm{O}$.

Prior to the procedure, all of the patients were submitted to MR venous angiography. Only those cases showing stenosis of the transverse sinus were submitted to cerebral angiography with manometry (-Fig. 1). The patients were assessed retrospectively. The following items of the clinical presentation were reviewed: headache, intracranial pressure documented by lumbar puncture in the lateral decubitus, and assessment of the optic papilla. A previous ophthalmologic assessment revealed bilateral optic papilledema in five patients and the presence of an optic disc with clearly defined borders in one case. The data were analyzed before and after the procedure, with a maximum follow-up of 16 months.

\section{Cerebral Venography and Stenting}

The patients were assessed previously for renal function and coagulation. During the procedure, the patients were given intravenous systemic anticoagulation with $110 \mathrm{UI} / \mathrm{Kg}$ of unfractionated heparin.

The patients were placed in the supine position on the fluoroscopy table and given general anesthesia. Cerebral angiography was performed using coaxial arterial catheterization with concomitant venous catheterization, in which the catheter was introduced into the internal jugular vein. The pressure within the venous sinus was measured using a transducer calibrated to the reference of the level of the midaxillary line.

Stenting was indicated based on pre and post-stenotic gradients $>8 \mathrm{~mm} \mathrm{Hg}$, as recommended by Ahmed et al in a similar study involving a representative sample. ${ }^{21}$ A selfexpanding stent was used and, after it was adequately placed into the stenosis, it was molded according to the length of the stenosis and the diameter of the transverse sinus (-Fig. 2). Manometry was repeated after stenting.

Antiplatelet therapy with clopidogrel $75 \mathrm{mg}$ daily and aspirin $100 \mathrm{mg}$ daily was used following the procedure. Clopidogrel was withdrawn after the first week. Cranial computed tomographies (CTs) were performed routinely after the procedures to rule out any complications.

\section{Results}

Between 2012 and 2013, 6 patients were submitted to shunting in the transverse sinus as a therapeutic measure for IIH. After the intervention, 3 patients (50\%) showed normal lumbar manometry values of $<25 \mathrm{~cm} \mathrm{H}_{2} \mathrm{O}$, and all had lower

Table 2 Diagnostic criteria for IIH established by Friedman \& Jacobsen

\begin{tabular}{|c|}
\hline Diagnostic criteria for IIH \\
\hline 1-In the presence of symptoms, these should only reflect generalized intracranial hypertension or papilledema. \\
\hline 2-In the presence of signs, these should only reflect generalized intracranial hypertension or papilledema. \\
\hline $\begin{array}{l}\text { 3-Documented intracranial hypertension, as measured by lumbar puncture with the patient in lateral decubitus } \\
\text { (pressures }>20 \mathrm{~cm} \mathrm{H} \mathrm{H}_{2} \mathrm{O} \text { in normal-weight individuals, and }>25 \mathrm{~cm} \mathrm{H} \mathrm{H}_{2} \mathrm{O} \text { in obese individuals are considered abnormal). }\end{array}$ \\
\hline 4-Normal CSF composition. \\
\hline $\begin{array}{l}\text { 5-Absence of evidence of hydrocephaly, structural lesions, with mass or vascular effect on MRI or CT, with contrast } \\
\text { for typical patients, and with complementation using venous MR angiography for other patients. }\end{array}$ \\
\hline 6 - Absence of other causes of intracranial hypertension identified. \\
\hline
\end{tabular}

Abbreviation: CSF cerebrospinal fluid; CT, computed tomography; IIH, idiopathic intracranial hypertension; MRI, magnetic resonance imaging. Note: Adapted from Friedman \& Jacobsen. ${ }^{20}$ 


\section{Patient referral sequence}

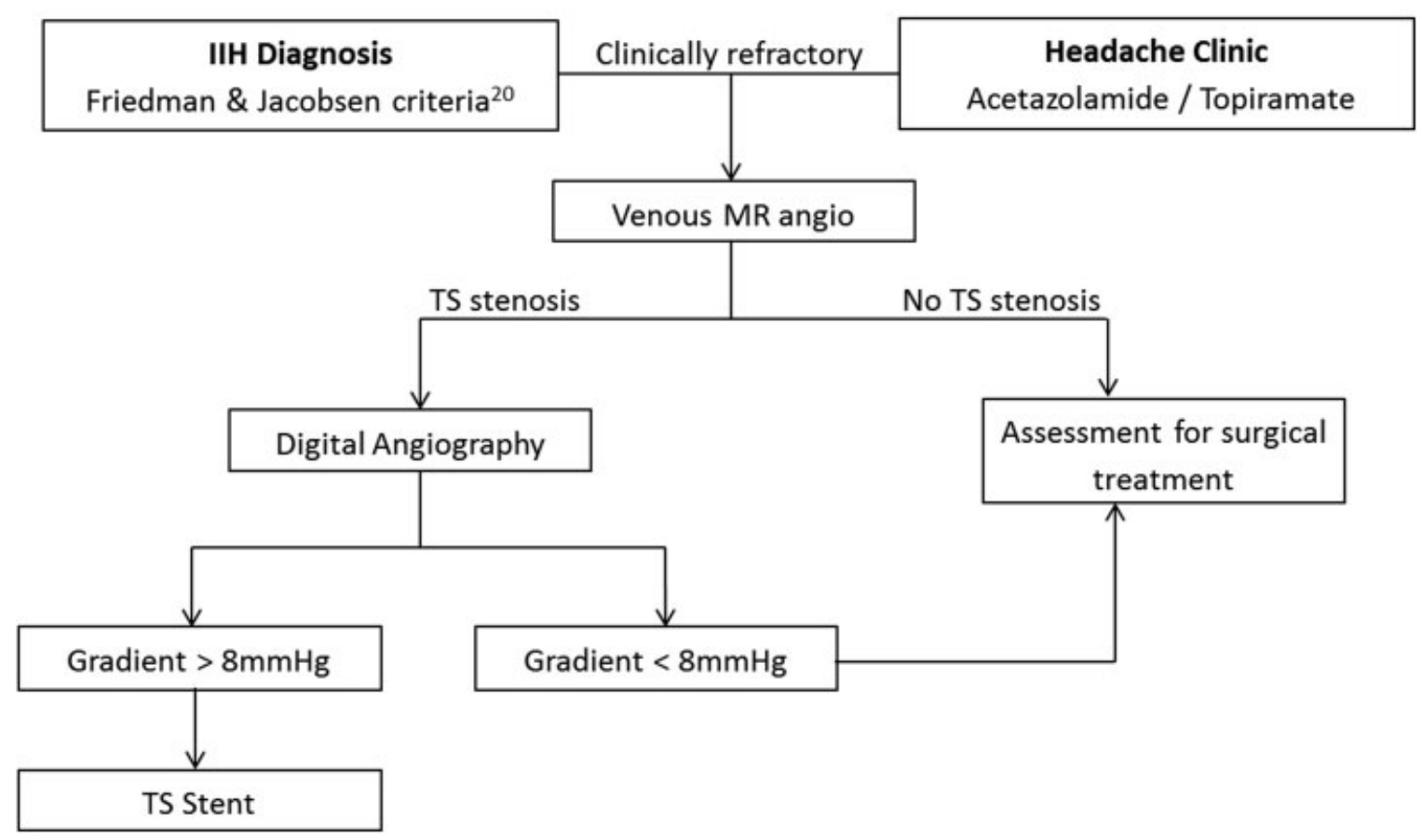

Fig. 1 Flowchart of the clinical investigation and treatment of IIH patients.

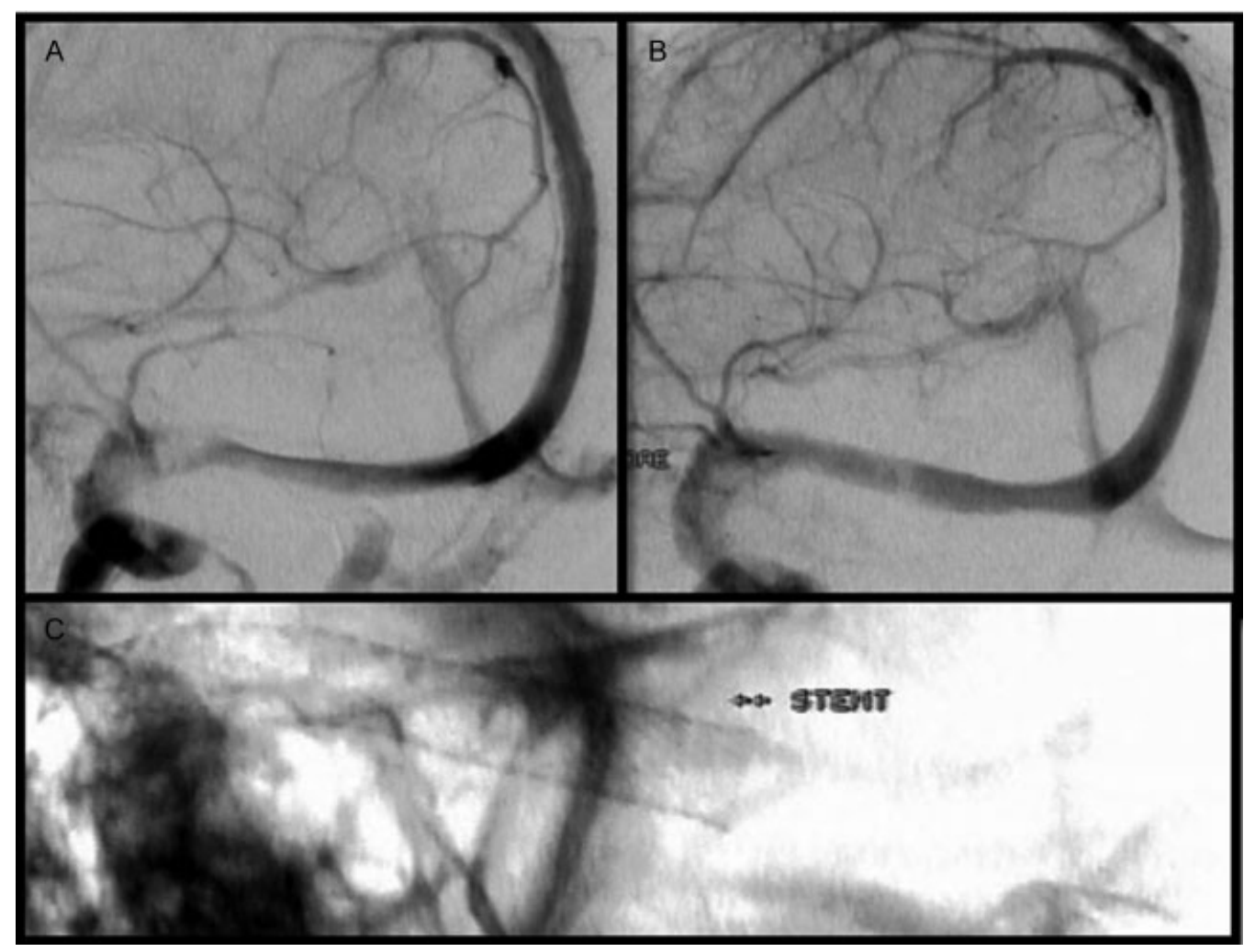

Fig. 2 (A) Pre-procedure cerebral venography showing the stenosis in the transition between the transverse and sigmoid sinuses. (B) Postprocedure cerebral venography showing the improvement of the stenosis after the stent placement. (C) Stent after implantation in the transverse sinus. 
lumbar manometry values, with a post-intervention mean of $24.7 \mathrm{~cm} \mathrm{H}_{2} \mathrm{O}$. The mean reduction in lumbar manometry value after the procedure was $15.3 \mathrm{~cm} \mathrm{H}_{2} \mathrm{O}$. One patient (patient 6) did not meet the criteria for transverse sinus stenting, having pressure gradients $<8 \mathrm{~mm} \mathrm{Hg}$. This patient showed an intermittent evolution, with a fluctuating course of signs and symptoms.

After the intervention, five patients showed an improvement on the fundoscopy exam, with clear optic discs. The assessment testing for impairment of the other cranial nerves led to the identification of two patients with impaired function of the abducens nerve prior to the procedure, which evolved with clinical improvement post intervention.

With regard to the pressure gradient between the proximal and distal limits to the transverse sinus stenosis, a preintervention mean of $12.3 \mathrm{~mm} \mathrm{Hg}$ was observed. The postintervention mean was $1.7 \mathrm{~mm} \mathrm{Hg}$, thus representing an average reduction of $10.6 \mathrm{~mm} \mathrm{Hg}$. The treatment target was the right transverse sinus in four cases, and the left transverse sinus in the remaining two patients. Two individuals (patients 2 and 3 ) had transverse sinus stenosis that met the criteria for bilateral stenting. In these cases, the side with the highest gradient was the target of the treatment.

Concerning the post-intervention clinical status, both patients showed improvements in their headaches. Four patients became asymptomatic (66.7\%), while the remaining 2 showed improvement but not full resolution of the headache (33.3\%). The improvement began within 24 hours of the procedure in these patients. In the first month, two of the asymptomatic patients (patients 4 and 7) had complaints of pulsatile headache, albeit at a lower intensity than before, located retro auricular and ipsilateral to the stented side. This symptom resolved spontaneously during the out-patient follow-up.

\section{Discussion}

Stenosis in the transition between the transverse and sigmoid sinuses is frequently observed in patients with IIH. Studies employing the use of venous MR angiography for diagnosis have revealed a greater prevalence of this condition among individuals with IIH compared with a control group of healthy individuals. ${ }^{14,22}$ Farb et al detected venous stenosis bilaterally in 27 out of $29 \mathrm{IIH}$ patients, and found the same abnormality in only 4 of the 59 patients from the control group. ${ }^{14}$ The observation of elevated pressure within the cerebral venous sinuses of these cases is consistent with the notion that a partial blockage of the cerebral venous drainage could play a key role in the physiology of the disease. ${ }^{12}$ However, refractory cases eligible for endovascular treatment are infrequent, and this fact justifies our small sample size, common to other studies about this topic.

Secondary intracranial hypertension has an underlying medical cause. In many situations, elevated venous pressure can be the physiological mechanism involved, as it occurs in dural venous fistulas, cerebral venous thrombosis of the sinuses or venous sinus compression. ${ }^{23}$ However, in the majority of IIH cases, cerebral angiography shows a narrowing of the transverse sinus, which does not reflect acute venous thrombosis. ${ }^{13}$ A pivotal question regarding transverse sinus stenosis in IIH is whether this abnormality is the cause or consequence of the elevated intracranial pressure. ${ }^{21}$ Mathematical models support the hypothesis that the transverse sinus is a compliant structure to the point of being vulnerable to extrinsic compression, which may obstruct the venous drainage, resulting in venous and intracranial hypertension. ${ }^{24}$ On the other hand, results published in recent years, which show clinical improvement in some patients after the reconstruction of the transverse sinus with endovascular stents, reinforce the hypothesis that the stenosis established in the sinus independently causes the venous flow blockage. ${ }^{13,22}$ These two alternatives may give rise to similar symptomatology, alone or concomitantly, explaining the variability in outcomes seen on the clinical assessment of patients.

The present study findings are consistent with the growing body of evidence on the endovascular option for the treatment of IIH. The first report of IIH treatment with the use of stents was published by Higgins et al in 2002, ${ }^{25}$ and it involved a 30 -year-old women with a 22-month prior history of headache, papilledema and transverse sinus stenosis visualized on venous MR angiography. Dilation was achieved by stenting, resulting in a reduced pressure gradient and improvement in symptoms. Based on this data, a growing number of studies investigating this topic have been conducted, in which the vast majority of patients were women. ${ }^{13,19,22}$ In a recent review, a group of Canadian researchers reviewed 8 studies and analyzed a total of 40 patients treated using the method. ${ }^{26}$ After stenting, $82.5 \%$ of the patients showed resolution or significant improvement of their headaches, and $91 \%$ of individuals exhibiting papilledema upon admission showed an improvement of this sign. ${ }^{26}$ Akin to the present investigation, headache ipsilateral to the stent occurred, an event observed in over $50 \%$ of the patients, and characterized as transient in most cases. Ahmed et al attributed this symptom to the distension of the transverse sinus after the procedure, and it generally improved after one week. ${ }^{21}$ This hypothesis can explain the transience of symptoms presented by patients 4 and 7 .

The analysis of the situation of some patients with bilateral stenosis and high pressure gradients on both sides reveals differences in approach. ${ }^{27,28}$ In the present study, we decided to perform the procedure on one sinus only, electing the side with the highest pressure gradient. The rationale for this conduct is grounded in the pro-thrombotic properties of stents, in which a unilateral approach precludes the risk for the patient of future bilateral thrombosis of the transverse sinuses. Higgins, ${ }^{28}$ in 2003, and Donnet, ${ }^{29}$ in 2008, reported bilateral stenting of the transverse sinus in two cases and one case respectively. Up to the date of the publication of the studies, no thrombosis was reported during the follow-up of these patients.

Endovascular therapy with the use of stents carries an inherent risk associated with serious complications, such as perforation of vessels, migration of the prosthesis, increased risk of thrombosis, and restenosis of the implantation site. Due to these risks, anticoagulation during the procedure and antiplatelet therapy after the intervention are necessary, with no consensus on the minimum duration of the antiplatelet therapy. ${ }^{29}$ In the present study, no post-intervention 
complications were seen, although studies involving larger samples have observed complications. Ahmed, ${ }^{21}$ in a study involving 52 patients, observed the emergence of a neurologic deficit after the intervention, secondary to an acute subdural hematoma and subarachnoid hemorrhage. Allergic reactions to acetylsalicylic acid and clopidogrel have also been observed in another two patients. ${ }^{21}$

The assessment of the response to the endovascular treatment for IIH is hard to interpret. ${ }^{26}$ The present study included only six cases in which stents were effectively implanted. In addition, the clinical course of IIH is highly variable, having a subacute or intermittent course. ${ }^{4}$ Another factor to take into account is the durability of the clinical improvement, in which a longer follow-up period is required for a more meaningful assessment. Evidence is needed from a randomized study that could exclude confounding variables such as weight loss, which can have a major influence on the clinical improvement of some patients. ${ }^{4,6}$

\section{Conclusion}

Patients refractory to clinical treatment must be submitted to the adequate imaging investigation. Angiography should be performed only after the detection of a transverse sinus stenosis on an MRI with venous study.

In cases of elevated pressure gradients, the endovascular therapy can promote a significant improvement in the symptoms of patients with IIH. However, the efficacy and safety of this procedure should be assessed by randomized studies involving larger samples.

\section{References}

1 Pearce JM. From pseudotumour cerebri to idiopathic intracranial hypertension. Pract Neurol 2009;9(6):353-356

2 Johnston I. The historical development of the pseudotumor concept. Neurosurg Focus 2001;11(2):E2

3 Giuseffi V, Wall M, Siegel PZ, Rojas PB. Symptoms and disease associations in idiopathic intracranial hypertension (pseudotumor cerebri): a case-control study. Neurology 1991;41(2 Pt 1):239-244

4 Shah VA, Kardon RH, Lee AG, Corbett JJ, Wall M. Long-term followup of idiopathic intracranial hypertension: the Iowa experience. Neurology 2008;70(8):634-640

5 Thambisetty M, Lavin PJ, Newman NJ, Biousse V. Fulminant idiopathic intracranial hypertension. Neurology 2007;68(3): 229-232

6 Wall M, George D. Idiopathic intracranial hypertension. A prospective study of 50 patients. Brain 1991;114(Pt 1A):155-180

7 Walker RW. Idiopathic intracranial hypertension: any light on the mechanism of the raised pressure? J Neurol Neurosurg Psychiatry 2001;71(1):1-5

8 Ball AK, Clarke CE. Idiopathic intracranial hypertension. Lancet Neurol 2006;5(5):433-442

9 Cognard C, Casasco A, Toevi M, Houdart E, Chiras J, Merland JJ. Dural arteriovenous fistulas as a cause of intracranial hypertension due to impairment of cranial venous outflow. J Neurol Neurosurg Psychiatry 1998;65(3):308-316
10 Biousse V, Ameri A, Bousser MG. Isolated intracranial hypertension as the only sign of cerebral venous thrombosis. Neurology 1999;53(7):1537-1542

11 Plant GT, Donald JJ, Jackowski A, Vinnicombe SJ, Kendall BE. Partial, non-thrombotic, superior sagittal sinus occlusion due to occipital skull tumours. J Neurol Neurosurg Psychiatry 1991;54(6):520-523

12 King JO, Mitchell PJ, Thomson KR, Tress BM. Cerebral venography and manometry in idiopathic intracranial hypertension. Neurology 1995;45(12):2224-2228

13 Karahalios DG, Rekate HL, Khayata MH, Apostolides PJ. Elevated intracranial venous pressure as a universal mechanism in pseudotumor cerebri of varying etiologies. Neurology 1996;46(1): 198-202

14 Farb RI, Vanek I, Scott JN, et al. Idiopathic intracranial hypertension: the prevalence and morphology of sinovenous stenosis. Neurology 2003;60(9):1418-1424

15 Lueck C, Mcllwaine G. Interventions for idiopathic intracranial hypertension. Cochrane Database Syst Rev 2002;(3):CD003434. doi: 10.1002/14651858.CD003434

16 Celebisoy N, Gökçay F, Sirin H, Akyürekli O. Treatment of idiopathic intracranial hypertension: topiramate vs acetazolamide, an open-label study. Acta Neurol Scand 2007;116(5):322-327

17 Burgett RA, Purvin VA, Kawasaki A. Lumboperitoneal shunting for pseudotumor cerebri. Neurology 1997;49(3):734-739

18 Pearson PA, Baker RS, Khorram D, Smith TJ. Evaluation of optic nerve sheath fenestration in pseudotumor cerebri using automated perimetry. Ophthalmology 1991;98(1):99-105

19 Arac A, Lee M, Steinberg GK, Marcellus M, Marks MP. Efficacy of endovascular stenting in dural venous sinus stenosis for the treatment of idiopathic intracranial hypertension. Neurosurg Focus 2009;27(5):1-8

20 Friedman DI, Jacobson DM. Diagnostic criteria for idiopathic intracranial hypertension. Neurology 2002;59(10):1492-1495

21 Ahmed RM, Wilkinson M, Parker GD, et al. Transverse sinus stenting for idiopathic intracranial hypertension: a review of 52 patients and of model predictions. AJNR Am J Neuroradiol 2011; 32(8):1408-1414

22 Higgins JNP, Gillard JH, Owler BK, Harkness K, Pickard JD. MR venography in idiopathic intracranial hypertension: unappreciated and misunderstood. J Neurol Neurosurg Psychiatry 2004; 75(4):621-625

23 Binder DK, Horton JC, Lawton MT, McDermott MW. Idiopathic intracranial hypertension. Neurosurgery 2004;54(3):538-551, discussion 551-552

24 Stevens SA, Previte M, Lakin WD, Thakore NJ, Penar PL, Hamschin B. Idiopathic intracranial hypertension and transverse sinus stenosis: a modelling study. Math Med Biol 2007;24(1):85-109

25 Higgins JN, Owler BK, Cousins C, Pickard JD. Venous sinus stenting for refractory benign intracranial hypertension. Lancet 2002; 359(9302):228-230

26 Bussière M, Falero R, Nicolle D, Proulx A, Patel V, Pelz D. Unilateral transverse sinus stenting of patients with idiopathic intracranial hypertension. AJNR Am J Neuroradiol 2010;31(4):645-650

27 Higgins JNP, Cousins C, Owler BK, Sarkies N, Pickard JD. Idiopathic intracranial hypertension: 12 cases treated by venous sinus stenting. J Neurol Neurosurg Psychiatry 2003;74(12):1662-1666

28 Donnet A, Metellus P, Levrier O, et al. Endovascular treatment of idiopathic intracranial hypertension: clinical and radiologic outcome of 10 consecutive patients. Neurology 2008;70(8):641-647

29 Malek AM, Higashida RT, Balousek PA, et al. Endovascular recanalization with balloon angioplasty and stenting of an occluded occipital sinus for treatment of intracranial venous hypertension: technical case report. Neurosurgery 1999;44(4):896-901 